\title{
DISCUSSION
}

\section{Comparison of site-specific and empirical correlations for drained residual shear strength}

\author{
CONNOR P. HAYDEN*, KATHRYN PURCHASE-SANBORN†, MANDAR DEWOOLKAR \\ and HISHAM T. EID ${ }^{\S}$
}

\section{Contribution by Hisham T. Eid}

The discusser has an interest in the topic of the paper (Hayden et al., 2018) on the ability of empirical correlations to predict the residual friction angle of samples from a specific site. In fact, he provided one of the few data sets used by the authors in their study. He also agrees with them that correlations should not entirely replace site-specific laboratory measurement wherever it is available. However, the discusser has a concern on the paper's general conclusion regarding the relatively poor performance of the considered correlations in predicting the measured residual friction angles. In the discusser's opinion, this is in particular not accurate for the correlation by Stark \& Eid (1994) and its updated versions (e.g. Eid, 1996; Stark \& Hussain, 2013; Eid et al., 2016). As the principal developer of this type of residual shear strength correlation, the discusser has been emphasising the fact that heavily overconsolidated clays, claystones and shales possess diagenetic bonding that results in particle aggregation. This aggregation usually survives the standard sample preparation procedure and consequently influences the measured index parameters. Eid (2001) clearly showed that sand-size and silt-size bits of indurated materials can survive the standard sample preparations for Atterberg limits and hydrometer tests, respectively, and are wrongly considered as sand and silt contents. As a result, these materials should be disaggregated by ball milling until all particles pass the standard sieve no. 200. In most cases, using a mortar and pestle to pass sieve no. 200 is not enough to disaggregate these indurated bits. Extensive experimental studies have been conducted specifically to correlate the indices of the indurated materials to those yielded using the standard procedures (e.g. Eid, 2006). Using the indices derived from the standard procedures influences the accuracy of their correlations to the results of shear strength testing in which the aggregated particles would be battered. Because of the significant effects of this issue on predicting the shear strength friction angles, Eid et al. (2016) and Eid \& Rabie (2017) encompassed the equations needed to adjust the index parameters of indurated materials in the figures of their correlations, as shown in Fig. 8 for the residual shear strength.

The authors described most of the Colorado natural samples as claystones and siltstones. As per the Dictionary of geological terms of the American Geological Institute (Bates \& Jackson, 1984), claystone is defined as 'An indurated clay having the composition of shale, but lacking the fine lamination of fissility', while siltstone is defined as 'A very

\footnotetext{
* The University of Auckland, Auckland, New Zealand (Orcid:0000-0003-4719-7253).

$\dagger$ School of Civil and Environmental Engineering, Georgia Institute of Technology, Atlanta, GA, USA.

t Civil and Environmental Engineering, The University of Vermont, Burlington, VT, USA.

$\S$ Department of Civil Engineering, Qatar University, Doha, Qatar.
}

fine-grained consolidated clastic rock composed predominantly of particles of silt grade'. For the commercial laboratory data set, the authors stated that the origin of individual samples is not available and the majority of the samples were overconsolidated. They also mentioned the too-general note made by the laboratory technician who conducted the related tests as 'disaggregation with mortar and pestle... seemed sufficient, so none of the samples was ball milled' (Hayden et al., 2018: p. 1102). In addition, most of the natural samples utilised in developing the other two data sets (i.e. sets from Stark \& Eid (1994) and Tiwari \& Marui (2005)) used in the analyses presented in Hayden et al. (2018) are of heavily overconsolidated clays, claystones, or shales. This is clear from the sample description provided in Stark \& Eid (1994), Tiwari \& Marui (2005), Tiwari et al. (2005) and Tiwari \& Ajmera (2015). As explained previously, most of these natural materials need to be ball milled for disaggregation and measurement of their index parameters. Disregarding this fact may have led to some errors in assessing the predicted residual friction angles and consequently affected the general conclusion of the paper.

Figure 9(a) shows a comparison between the residual friction angles measured by Hayden et al. (2018) and those predicted using the correlation of Fig. 8. The index parameters of Colorado natural samples (i.e. samples of claystones and siltstones) were adjusted according to the equations encompassed in Fig. 8. A reasonable agreement can be clearly seen between the measured and predicted residual friction angles. The agreement is very comparable to those shown in Fig. 2 of Hayden et al. (2018) using the two site-specific equations suggested by the authors for predicting the residual friction angles of Colorado natural samples. The correlations of Wesley (2003) and Mitchell \& Soga (2005) do not show such a degree of agreement (Figs 9(b) and 9(c)). For determining the predicted residual angles shown in Figs 9(b) and 9(c), the average curve for the upper and lower bounds of the Wesley (2003) correlation was used, while interpolation between the activity upper and lower bounds was used when utilising the Mitchell \& Soga (2005) correlation. The indices derived from the standard procedures were also used in predicting those residual friction angles. The results shown in Fig. 9 suggest that - even for a site with a significant soil variability, such as that described in Hayden et al. (2018) - a reasonable prediction can be made for the drained residual friction angles through using empirical correlations that consider the induration, plasticity and composition of soil, as well as the level of effective normal stress. This suggestion is strongly supported by the study results presented in Eid et al. (2016) on the suitability of using empirical correlations to estimate the backcalculated residual friction angles reported in the literature for 54 reactivated landslides.

It should be noted that the slight difference (considering the repeatability of the ring shear results) reported by the authors between the residual friction angles measured for the samples disaggregated to pass sieve no. 40 and those 


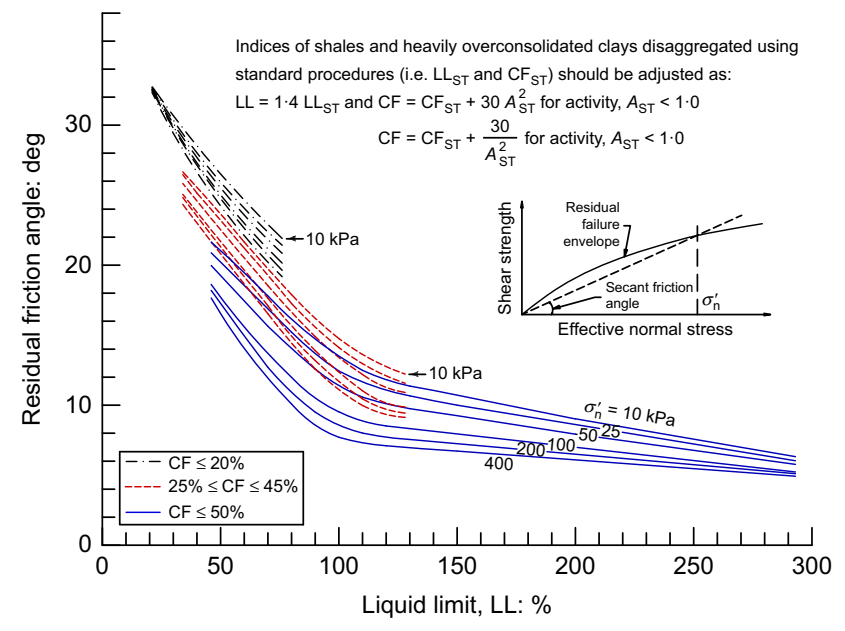

Fig. 8. Drained secant residual friction angle correlation as a function of liquid limit, clay-size fraction and effective normal stress (after Eid et al., 2016)

disaggregated to pass sieve no. 200 may be attributed to the two sources of error usually associated with the ring shear testing procedure followed by the authors. The first is related to adding additional soil to the consolidated specimen to make it flush with the top of the specimen container, as recommended by Stark \& Vettel (1992). This step requires lifting the loading platen that is usually stuck to the soil specimen due to applying high consolidation pressure $\left(\sigma_{\mathrm{n}}^{\prime}=700 \mathrm{kPa}\right)$. Such lifting may damage the consolidated specimen when made vertically or create a pre-existing shear surface when accompanied by axial rotation. The second source of error can be attributed to using a bevelled plate in a trial to reduce the wall friction. The intersection of the $45^{\circ}$ bevelled inner and outer sides of the porous plate with its serrated base creates several corridors - with a width equal to the serration depth - along most of the inner and outer perimeters of the porous plate. Significant extrusion of soil can occur through these corridors during the consolidation and shearing stages. This may lead to uneven stress distribution on top of the sheared specimen and a reduction in the contact area between the soil specimen and the overlaying serrated plate. Using bevelled top plates is more suited to soil interface testing (Eid et al., 2015; Eid, 2019).

The discusser also has a concern regarding the values of the secant residual friction angles estimated at $\sigma_{\mathrm{n}}^{\prime}=100 \mathrm{kPa}$ by the authors for the natural soils tested by Tiwari \& Marui (2005). In the original reference, only the friction angle yielded from a linear regression analysis - was reported for each soil, while the cohesion intercept was presented just as a range (between 0 and $10 \mathrm{kPa}$ ) with an indication that most of the values were below $5 \mathrm{kPa}$.

\section{Authors' reply}

The authors appreciate the discusser's interest in the paper and express their thanks again for providing some of the data analysed in the paper. The discusser raises several concerns, which are addressed below in the order they are raised.

The discusser provides a review of ball milling and concludes that 'Disregarding this fact may have led to some errors...'. However, the paper does not 'disregard' the importance of ball milling highly indurated specimens, but instead explains why the specimens collected as part of this study (i.e. Table 1) were intentionally not ball milled. As stated by Stark et al. (2005: pp. 581-582)

A judgment decision is usually made on whether a material should be ball milled or not. This decision is

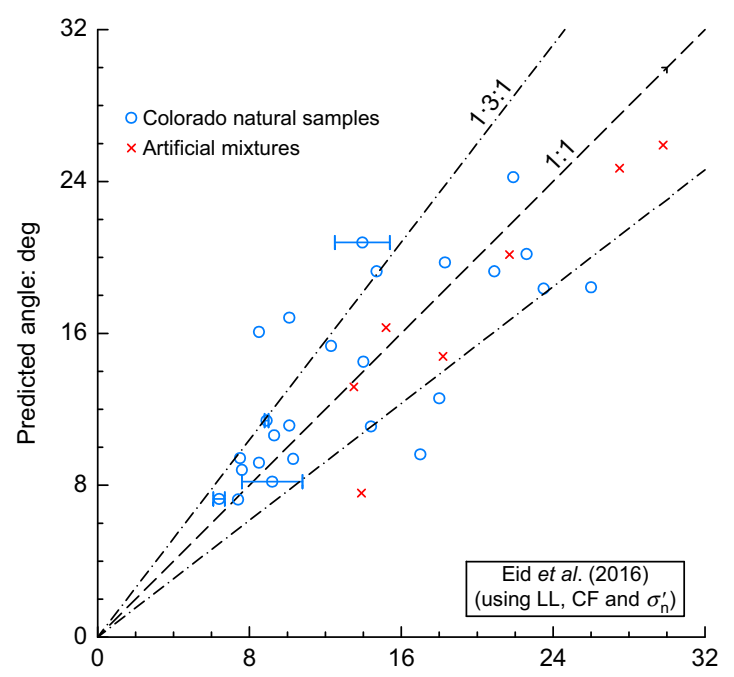

(a)

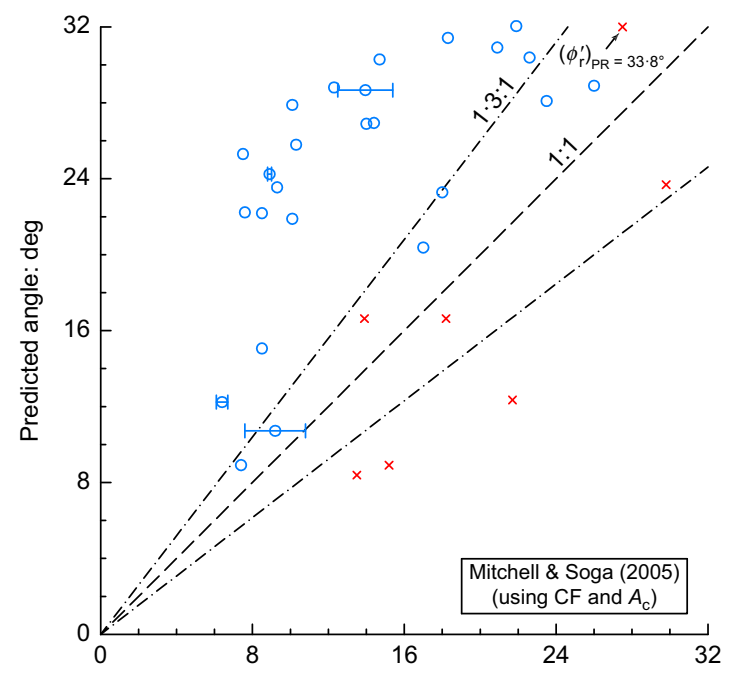

(b)

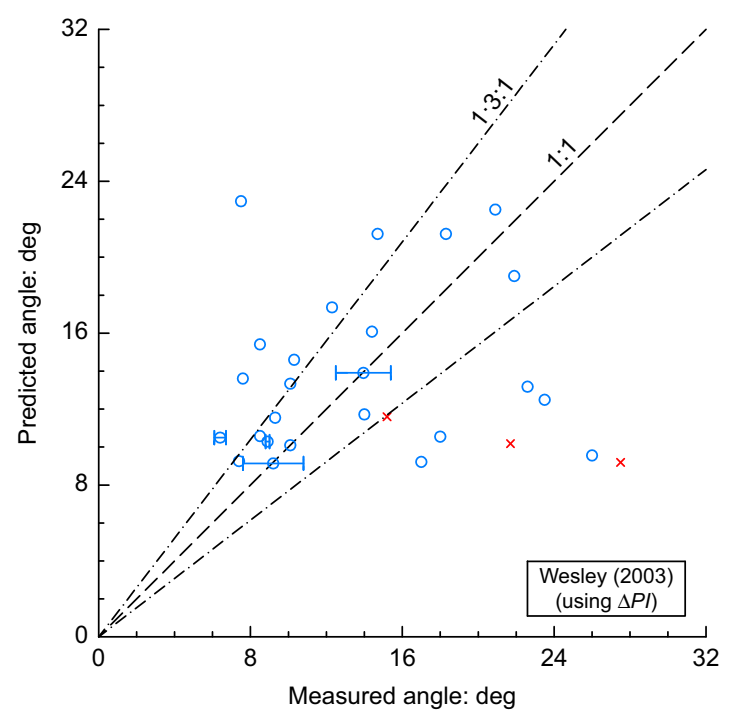

(c)

Fig. 9. Measured drained residual friction angles of natural samples and artificial mixtures compared with those predicted using different empirical correlations

made after examination of the chunks of claystone, mudstone, shale, or overconsolidated clay and determining whether the chunks can be sufficiently broken down with a mortar and pestle to disaggregate the clay particles. 
As explained in more detail in the paper, the samples were not highly indurated, as demonstrated by grinding four of the seemingly most indurated samples to pass the no. 200 sieve (i.e. Table 2) and comparing the index test results with the same samples processed following the ASTM standards. Despite being among the most indurated samples, this additional processing did not significantly improve the fit of the Stark \& Hussain (2013) correlation. As already stated in the paper, many of the samples contained a significant proportion of sand, and Stark et al. (2005) point out that ball milling is not performed on samples that are sufficiently disaggregated with a mortar and pestle, as this would change the gradation of the soil. Accordingly, the samples were not ball milled as they were not highly indurated and many had significant sand content.

The discusser provides Fig. 9 showing predictions based on index parameters adjusted from ASTM standard measurements to ball-milled estimates. However, as discussed above and in the original paper, the samples were not highly indurated, so applying an adjustment factor, such as Stark et al. (2005) or Eid et al. (2016) would overestimate the liquid limit and clay-size fraction. The example given in the paper for sample 15 still applies to the Eid et al. (2016) adjustment factors, except the predicted ball-milled liquid limit would be 73 (instead of 72 from the Stark et al. (2005) correlation), which significantly overestimates the actual liquid limit of 56 measured after grinding the specimen to pass the no. 200 sieve.

Even if applying the ASTM-to-ball-milled adjustment factor was warranted, certain samples still deviate significantly from the Eid et al. (2016) correlation. For example, there are samples that have predicted residual friction angles of around $16^{\circ}$ but measured residual friction angles of around $8^{\circ}$, and using a correlation in these cases could be disastrous in engineering practice. The authors agree with the discusser that the Eid et al. (2016) correlation performs better than the Mitchell \& Soga (2005) correlation. However, simply taking the average of the upper and lower bounds of the Wesley (2003) correlation seems unreasonable, as this oversimplifies the variability that is incorporated into that correlation. Finally, with regard to the discusser's comment on back-calculated residual friction angles supporting the Eid et al. (2016) correlation: with the significant uncertainties inherent in strength estimates from back-analyses of reactivated landslides, it seems doubtful that these should be relied upon more than actual ring shear data in assessing the suitability of correlations.

The discusser suggests two sources of error may result from the ring shear test procedure employed in this study. First, the discusser suggests that the 'flush' method as recommended by Stark \& Vettel (1992) may 'damage' the soil specimen; however, given that at the residual condition any initial soil structure has been destroyed and the specimens are already remoulded when placed into the annular specimen container, it is not clear what the discusser refers to. In any case, the top platen was removed carefully before adding additional soil and reconsolidating as recommended by various authors (e.g. Stark \& Vettel, 1992; Meehan et al., 2007), and the shear plane for each specimen was observed just below the interface with the top platen, as expected in the Bromhead apparatus. The second source of error does not apply to the equipment used in this study as the top platen did not have a serrated base and the bevel was stopped slightly before intersecting the bottom edge of the top platen, leaving a slight lip. As a result, bevelling had no effect on the bottom surface of the top platen.

The discusser points out that the Tiwari \& Marui (2005) data set uses residual friction angles based on linear regression, which includes some small cohesion (specific values not published, but less than $5 \mathrm{kPa}$ for most specimens). Using the residual friction angles directly as presented by Tiwari \& Marui (2005) could result in a small underestimate of the secant residual friction angle at $100 \mathrm{kPa}$ normal stress, but not much can be done given that more specific cohesion data are unavailable. However, even if the cohesion intercept was $5 \mathrm{kPa}$ for a given specimen, this would result in the secant residual friction angle at $100 \mathrm{kPa}$ being at most around $3^{\circ}$ higher than the residual friction angle plotted in Figs 4, 6 and 7, so this would not change the overall conclusion.

\section{REFERENCES}

Bates, R. L. \& Jackson, J. A. (eds) (1984). Dictionary of geological terms. New York, NY, USA: Random House.

Eid, H. T. (1996). Drained shear strength of stiff clays for slope stability analyses. $\mathrm{PhD}$ thesis, University of Illinois at Urbana-Champaign, Urbana, IL, USA.

Eid, H. T. (2001). Correlation between shale index properties derived from different sample preparation procedures. Proceedings of the 15th international conference on soil mechanics and geotechnical engineering, Istanbul, Turkey, vol. 1, pp. 77-80.

Eid, H. T. (2006). Factors influencing determination of shale classification indices and their correlation to mechanical properties. Geotech. Geol. Engng J. 24, No. 6, 1695-1713.

Eid, H. T. (2019). Undrained interface shear strength of fine-grained soils for near-shore marine pipelines. ASTM Geotech. Testing J. https://doi.org/10.1520/GTJ20180188.

Eid, H. T. \& Rabie, K. H. (2017). Fully softened shear strength for soil slope stability analyses. Int. J. Geomech. 17, No. 1, 04016023-1-04016023-10.

Eid, H. T., Amarasinghe, R. S., Rabie, K. H. \& Wijewickreme, D. (2015). Residual shear strength of fine-grained soils and soil-solid interfaces at low effective normal stresses. Can. Geotech. J. 52, No. 2, 198-210.

Eid, H. T., Rabie, K. H. \& Wijewickreme, D. (2016). Drained residual shear strength at effective normal stresses relevant to soil slope stability analyses. Engng Geol. 204, 94-107.

Hayden, C. P., Purchase-Sanborn, K. \& Dewoolkar, M. (2018). Comparison of site-specific and empirical correlations for drained residual shear strength. Géotechnique 68, No. 12, 1099-1108, https://doi.org/10.1680/jgeot.17.P.200.

Meehan, C. L., Brandon, T. L. \& Duncan, J. M. (2007). Measuring drained residual strengths in the Bromhead ring shear. Geotech. Testing J. 30, No. 6, 466-473.

Mitchell, J. K. \& Soga, K. (2005). Fundamentals of soil behavior, 3rd edn. New York, NY, USA: Wiley.

Stark, T. D. \& Eid, H. T. (1994). Drained residual strength of cohesive soils. J. Geotech. Engng 120, No. 5, 856-871.

Stark, T. D. \& Hussain, M. (2013). Empirical correlations: drained shear strength for slope stability analyses. J. Geotech. Geoenviron. Engng 139, No. 6, 853-862.

Stark, T. D. \& Vettel, J. J. (1992). Bromhead ring shear test procedure. Geotech. Testing J. 15, No. 1, 24-32.

Stark, T. D., Choi, H. \& McCone, S. (2005). Drained shear strength parameters for analysis of landslides. J. Geotech. Geoenviron. Engng 131, No. 5, 575-588.

Tiwari, B. \& Ajmera, B. (2015). Reduction in fully softened shear strength of natural clays with $\mathrm{NaCl}$ leaching and its effect on slope stability. J. Geotech. Geoenviron.Engng 141, No. 1, 04014086.

Tiwari, B. \& Marui, H. (2005). A new method for the correlation of residual shear strength of the soil with mineralogical composition. J. Geotech. Geoenviron. Engng 131, No. 9, $1139-1150$.

Tiwari, B., Brandon, T. L., Marui, H. \& Tuladhar, G. R. (2005). Comparison of residual shear strengths from back analysis and ring shear tests on undisturbed and remolded specimens. J. Geotech. Geoenviron.Engng 131, No. 9, 1071-1079.

Wesley, L. D. (2003). Residual strength of clays and correlations using Atterberg limits. Géotechnique 53, No. 7, 669-672, https://doi.org/10.1680/geot.2003.53.7.669. 